\title{
Couple versus Single Mother Group Treatment: A Comparative Study
}

\author{
Maly Danino \\ Nitzan Organization \\ The Israeli Institute for Learning Disabilities \\ Zippi Shechtman \\ Nitzan Organization \\ The Israeli Institute for Learning Disabilities
}

\begin{abstract}
This study compared couple versus single-mother treatment in group. Ninety-three participants from nine small groups received treatment in one of two conditions: mothers (47) and 23 couples $(n=46)$. Results showed positive pre-post outcomes on stress and parental coping for participants in both conditions, with no difference between them. However, differences were found at post-follow up (after six months), with parents treated as couples managing to retain gains following treatment, compared with mothers treated alone, who even showed some deterioration with time. Only one gender difference was found-fathers were less motivated to engage in treatment in all three time measurements. Regarding the important role fathers have in their child's development and the positive gains when treated as a couple, fathers should be encouraged to engage more in treatment, and an interpersonal group of an expressive-supportive modality may be a viable way for fathers to do so.
\end{abstract}

\section{COUPLE VERSUS SINGLE-MOTHER GROUP TREATMENT}

Parents of children with LD and ADHD experience relatively more parenting stress, depression, marital distress, and lower levels of parenting self-esteem relative to other parents (Chronis, Gamble, Roberts, and Pelham, 2006). Indeed, group training is widely offered to parents (Dodge, 2009), mostly of cognitive-behavioral or behavioral principles. However, unequal participation of fathers and mothers and a lack of data exist on the impact of treatment on fathers (Fletcher, Freeman, Matthey, 2011). The aim of this study is to investigate the contribution of father participation in group treatment for parents of children with LD and ADHD.

Parental behavior directly links to children's behavior (Barkley, 2006). Particularly, parents' harsh or inconsistent discipline, inadequate supervision, and a lack of warm, positive relationship have been shown to increase children's behavior problems and later lead to antisocial behavior and criminal activity (Fergusson, Horwood, \& Ridder, 2005; Pfiffner, McBurnett, Rathouz, \& Judice, 2005; Pheula, Rohde, \& Schmitz, 2011). Parents of children of LD/ADHD are under constant stress (Al-Yagon, 2007) and face daily difficulties that lead them to be inconsistent with their children, often angry and hostile (Cussen, Sciberras, Ukoumunne, \& Efron, 2012). According to the self-determination theory (Ryan \& Deci, 2000), harsh discipline interferes with the basic needs of children for autonomy and results in unhappy and disturbed child behavior. Indeed, a longitudinal study showed that harsh discipline and psychological control inhibits the development of a child's autonomy, and links to children's externalizing and internalizing problems, particularly when the father is involved in such parenting style (Lansford, Laird, Pettit, Bates, \& Dodge, 2009). Moreover, many of the parents 
of such children are also diagnosed with such disabilities, which may lead to their ineffectiveness as parents. Fathers diagnosed with ADHD were found harsher in their parenting than those with no ADHD. Mothers were found to pay less attention to routines, resulting in "home chaos" (Mokrova, O'Brien, Calkins, \& Keane, 2010). In that study, fathers' symptoms were significantly related to inconsistent discipline, low involvement, and both supportive and non-supportive responses to child negative emotions. Mothers' symptoms were related to parenting effectiveness, to inconsistent disciple and non-supportive response to child negative emotions. It appears that mechanisms governing parenting in mother and father differ from one another (Parke, 2002), yet, parenting with mothers is more often studied.

Father involvement in child growth is important in all aspects of the child's functioning: cognitive, social, and emotional (Fabiano, 2007). Yet the literature suggests that fathers are less involved in treatment. For example, according to Budd and O'Brien (1982), in 12 years of 749 participating families, only $13 \%$ were fathers. Lack of data on father participation appears also in the more recent studies (Fletcher, Freeman, \& Matthey, 2011). For example, in the Shechtman and Gilat (2005) study, there were only three fathers of 57 families involved in the treatment. Moreover, the results for fathers participating in interventions are less positive. Fletcher and colleagues (2011) researched the impact of the Triple P-Positive Parenting Program based on a meta-analysis. He found a positive effect of the program but mothers had significantly greater improvement than fathers. Similarly, Treacy, Tripp and Baird (2005), studied the impact of a cognitive-behavioral program on mothers and fathers. Initially only about one-third of the sample were fathers, and they significantly gained less than mothers on parental stress and parenting stile. Danforth, Harvey, Ulaszek, and McKee (2006) also found this behavioral program effective in general but more so for mothers. They argue that the lack of father involvement made it difficult to gain accurate understanding of the efficacy of the program for fathers.

These findings cause concern, especially given that it is now widely accepted that father parenting has an important influence on children's development and it is separate to that of the mother (Lamb, 2004). In addition, fathers' participation in a behavioral parent training (BPT) program improved maintenance of behavior change in children and co-parenting (mother and father supported each other's parenting) (Schoppe-Sullivan, Weldon, Cook, Davis, \& Buckley, 2009). Furthermore, in the Shechtman and Gilat (2005) study, mothers gained on a number of variables, but, interestingly, fathers who were not involved directly in the treatment also gained on most variables in his relationship with the child of LD/ADHD, as well as with other children in the family. This finding was interpreted as support of co-parenting.

Recognizing the important role of parents as a change agent of child behavior, group treatment to parents of children with LD/ADHD is widely offered. Danforth et al., (2006) believe that such parents will prefer group treatment to individual treatment, which is also cost and time effective (Cunningham, Bremner, \& Boyle, 1995). Such groups are mostly of a psychoeducational type, based on cognitive-behavioral theories and primarily geared towards parent training. Some well-known programs are more comprehensive and inclusive of parental needs, as well. Such are, for example, "Incredible Years" (Webster-Stratton, \& Reid, 2010) and "The Triple P" Positive Parenting Program (Wiggins, Sofronoff, \& Sanders, 2009).

We offer a counseling type group intervention (in contrast to a psychoeducational group), in which the parent rather than child is the focus of attention. As in other related programs, the goals of the intervention are to help parents reduce stress and improve relationships with their children but in a more experiential rather than teaching style. The therapeutic factors 
identified by Yalom (Yalom \& Leszcz, 2005) are widely present, particularly catharsis, cohesiveness, and interpersonal learning. Other factors such as universality, hope, and imitative behavior are also frequently present in such groups. Thus, learning occurs through experiencing new relationships, a new self, and learning from one another. Interpersonal groups differ in their focus. According to the typology suggested by Kivlighan and Holmes (2004), there are four types of groups: affective/insight; affective-support; cognitive insight; cognitive support. Our groups best classify as affect-support groups. Therefore, we tend to refer to our groups as the expressive-supportive modality-the high focus on expressing emotions in a fully supportive social climate. However, this does not exclude developing insight and learning processes. In two studies that previously utilized this modality with parents, results indicated reduced stress, improved perception of the child, and improved parenting coping strategies (Danino \& Shechtman, 2012; Shechtman \& Gilat, 2005). The current study is an extension of the Danino and Shechtman (2012) study, in which we compared individual and group treatment; in the current study, we explore the impact of a group intervention on fathers and mothers separately, in two treatment conditions: single parent participation and couple participation. Based on the current literature, we hypothesized:

1. Mothers will show better outcomes than fathers on the dependent variables (stress, parenting style, and motivation to engage in treatment).

2. Couples will show better outcomes than single parents on these dependent variables.

\section{Participants}

\section{METHOD}

Participants were 93 parents of children with LD in group counseling, sixty-four mothers (69\%) and 29 fathers (31\%). Children's ages ranged between six and 18 years, and 71 of them were boys (76\%). Forty-one parents believed they also have an LD, and three additional parents actually were diagnosed with ADHD. Parents participated in nine small groups, led by nine therapists, with six to 12 parents per group. Pre and post data were full, while 55 parents (59\%) were available at follow up.

Therapists were 31 to 55 years old, all with an educational background in psychology, social work, or educational counseling. They received a year of training in group intervention of an expressive-supportive modality (Shechtman, 2007).

\section{Process}

This study is part of a larger investigation of group intervention compared to individual treatment (Danino \& Shechtman, 2012). In the study, outcomes following group or individual treatment were compared with a control group. Results indicated that both treatments produced more favorable results than the control group. Thus, validity of the intervention has been established. The current study uses only the group sample and compares outcomes for single versus couple participation and for mothers and fathers.

Parents were recruited through Nitzan, a national institute for children with LD/ADD/ADHD. Parents bring their children to the center for diagnosis and treatment. Parents who displayed a need for assistance with their children's behavior were placed in small groups based on their geodemographic.

In total, there were nine groups that operated in 12 weekly 2-hour sessions. The therapists were all trained in the expressive-supportive modality in a yearly training program and received group supervision throughout the treatment period. 
Parents completed the questionnaires in Nitzan Center before treatment (following the intake interview), at termination (last session), and six months later, in a group gathering aimed to follow up on parents' progress. The last two measurements took place in a group format. Couples completed the questionnaires separately.

\section{Instruments}

The Parenting Stress Index-Short Form (PSI-SF) measured parental stress in parent-child interactions (Abidin, 1995). The short form includes 36 items such as "I find myself giving up more of my life to meet my child's needs than I expected." Responses are given on a 5-point scale (strongly agree to strongly disagree), with a high score indicating higher levels of parental stress. Test-retest reliability over a one-year interval ranged from (.55 to .70, and reported internal consistency ranged from .80 to .89 (Abidin, 1995). Validity of the short form was based on a comparison with the full scale ( $\mathrm{r}$ tanged from .73-.92) (Moran et al., 1992). The scale has been used in Hebrew in previous studies (e.g., Danino \& Shechtman, 2012; = .93). In the current study: $\alpha=.91$.

Parental coping was measured by the Coping with Children's Negative Emotional Scale (CCNES) (Fabes, Eisenberg, \& Benzweig, 1990), which measures parents' responses to 12 difficult situations that their child may face (such as being teased by peers or embarrassing oneself in public). The scale contains three negative responses (distress, punitive, minimization), for example, "I tell my child that if he starts crying, he will have to go to his..." and three positive responses (encourage, emotion focused, and problem focused) for example, "I comfort my child and try to make him feel better"). For each situation, mothers were asked to rate on a 7-point scale how likely they would react with negative or positive response. Construct validity has been demonstrate in several studies. Eisenberg and Fabes (1994) found associations between parent reactions and children's social competence. Shechtman and Birani-Nasaraladin (2006) found correlations between children's reduced aggression and change in mothers' responses (e.g. $r=.60$ with encouragement). Test-retest reliability ranged from .60 to .90 (Fabes et al., 1990). In the Danino and Shechtman study (2012) internal consistency on a Hebrew version was .88 and .93 and in the current study CCNES positive: $\alpha=.90$ and CCNES negative: $\alpha=.86$.

Intention to participate in treatment was measured by the Self-Disclosure Index (SDI; Miller, Berg, \& Archer, 1983). Participants indicated the extent to which they intend to disclose on a 10 -item scale ranging from 0 (not at all) to 4 (Fully and completely). For example, "What I like or dislike about myself" and "My close relationships with others." The reported internal consistency ranged from .86 to .93. In the Toren and Shechtman (2010) study, it was .87. Intention to disclose was related to risk-taking intentions $(r=.35, p<.001)$ and to bonding with the therapist $(r=.28, p<.001)$ (Toren $\&$ Shechtman, 2010). In the current study, $\alpha$ was .90 .

\section{Intervention}

The group intervention was of a supportive-expressive modality. This modality focuses on emotional expressiveness in a highly supportive climate. In terms of group therapy categorization (Kivlighan \& Holmes, 2004), this modality can be characterized as affectivesupport group. The parent is the focus of the intervention (rather than the problem child), aiming toward their parental style, reducing parental stress and improving coping strategies through self-expressiveness supported by the group. This should further lead to selfawareness, learning about their parental style, and making changes in their relationship with their child when needed. These are process-oriented groups but semi-structured. All groups followed a structured manual to secure adherence to the program. In each session, a specific topic was introduced and parents shared their experiences and learned from one another. 
Topics included the meaning of being a parent of a child with LD/ADHD; the difficulties of the child; the dialog between parent and child; difficulties within the family; the parent's vision of the child's future; and coping with the school system.

\section{DATA ANALYSIS}

Data analysis was conducted with SPSS (version 22). Due to the nested design (parents within small groups), data were analyzed with mixed hierarchical models to account for the dependency of observations. Analyses of change included three levels: time within the individual, the individual level, and the small group. Change was examined by group (2) (one parent / couple; mother / fathers) and time (3) (pre, post, follow up). Post hoc comparisons were based on estimated marginal means.

Due to dropout from post to follow-up measurement, change in the parents' outcome variables was examined with two separate sets of analyses: one for pre-post differences and the other for post-follow up differences. This strategy was applied in order to maintain the authenticity of the data on the one hand and not to lose participants on the other. Further, due to the relatively small sample, in order not to inflate the alpha level, total scores of PSI and CCNES were used, rather than sub-scale scores.

\section{Preliminary results}

\section{RESULTS}

No differences were found in the study variables at pretest by the parent's gender, the child's gender, whether the child was diagnosed with ADHD, and whether follow-up data were available. Likewise, no pretest differences were found between participating parents as an individual versus as a couple, and between fathers and mothers on the stress index and on parenting. A significant difference between fathers and mothers on motivation was found, with mothers scoring higher on the initial score $F(1,84.33)=5.45, p=.022, \eta^{2}=.060$.

A significant correlation was found between the child's age and the total PSI ( $r=.25, p=.015)$, and thus the child's age was controlled in all the analyses.

\section{Counseling one parent versus the couple}

\section{MAIN RESULTS}

The first hypothesis suggested parents participating as couples in the group would gain more on the stress index and on parenting behavior. Table 1 presents means and standard deviations of the study variables by type of participation in group counseling (one parent / couple). Results of the statistical analyses are presented in Table 2.

Pre-post comparisons revealed a significant main effect for time for the total score of PSI, as well as for the scores of both the positive and negative coping parental behaviors (CCNES). No significant group by time interactions were found. That is, a significant decrease was noted in parental stress and negative coping behaviors during the intervention, as well as a significant increase in positive coping behaviors. No difference was detected in the change experienced by type of participation in counseling (one parent / couple).

Post to follow-up comparisons reveal a different picture. Regarding PSI, a significant increase was noted among parents who participated in the intervention as one parent $(F(1,87.58)=$ 14.04, $p<.001, \eta^{2}=.228$ ), yet no change was noted for those who participated in the intervention as couples $\left(F(1,87.58)=0.16, p=.688, \alpha^{2}=.003\right)$. That is, participating couples managed to retain gains achieved in counseling, yet stress increased (above its initial level) among parents who participated in the intervention alone, without their partners. 
Likewise, regarding parental positive coping behaviors (CCNES) a significant decrease was noted among parents who participated in the intervention as one parent $(F(1,87.86)=4.71, p$ $\left.=.033, \eta^{2}=.083\right)$, yet no change was noted for those who participated in the intervention as couples $\left(F(1,87.86)=0.17, p=.681, \eta^{2}=.003\right)$. Again, participating couples managed to retain gains achieved in counseling, yet positive coping behaviors decreased (below their initial level) among parents who participated in the intervention alone, without their partners.

No significant time by group interaction was noted for parental coping negative behaviors (CCNES), such that gains achieved during the intervention were retained for both sub-groups.

In summary, the only significant effect concerning difference between couple and single parent treatment was observed from post to follow up; that is, couples retained their gains and progressed after termination more than single-therapy parents.

The second hypothesis suggested that mothers would gain more than fathers on the study variables. Results of the analysis are presented in Table 3.

Pre to post differences were significant for the time main effect, as in Table 2, yet all pre to post parent's gender by time interactions were non-significant. Post to follow-up differences were significant only for the total score of PSI for the main effect of time $(F(1,79.22)=8.67, p=.004$, $\left.\eta^{2}=.143\right)$. Other time differences were not significant, and all parent's gender by time interactions were non-significant as well. That is, pre to post decrease in stress, and improvement in coping behaviors, were significant for mothers and fathers alike. Post to follow up increase in stress was significant for mothers and fathers alike, and change achieved during counseling in coping behaviors was retained at follow up, among mothers and fathers alike.

Regarding motivation to receive treatment results indicated first, pre-score differences: $F(1,84.33)=5.45, p=.02, \eta^{2}=.06$. Pre to post, and post to follow up significant main effects for gender on intention to disclose: (pre to post: $F(1,177.77)=10.79, p<.001, \eta^{2}=.113$; post to follow up: $\left.F(1,101.98)=7.91, p=.006, \eta^{2}=.142\right)$. Overall, gender differences on intention: $F(1,234.98)=17.89, p<.001, \eta^{2}=.07$. That is, mothers' intention to disclose was higher than fathers at all times.

\section{DISCUSSION}

The purpose of the study was to investigate the contribution of couple versus single parent participation in group treatment for parents of children with LD. From the initial data, it became clear that fathers are less involved in treatment, as suggested in the literature (Fletcher et al., 2011). Only one-third of the participants were fathers, despite the importance of fathers on children's functioning (Fabiano, 2007; Lamb, 2004; Lonsdorf et al., 2009). Moreover, a great number of parents were also diagnosed with ADHD, which makes it difficult for them to be effective parents (Mokrova et al., 2010). Moreover, the only initial difference between fathers and mothers was revealed on the self-disclosure measure: Fathers scored significantly lower. This particular measure was used to tap the motivation to get involved in treatment (Moran et al., 1982). The result suggests that fathers were less interested in counseling than mothers. They might have attended because of external spousal pressure, as suggested by Schoppe-Sullivan (2009), but lack of motivation for therapy is a crucial factor in treatment success (Clarkin \& Levy, 2004; Yalom \& Leszcz, 2005), as concluded by Tallman and Bohart (1999):

Clients who are motivated, hold expectations that therapy will help, and have a clear set of goals, will be more likely to profit from being in therapy (p. 104). 
Testing the hypotheses produced three major results. 1. Parents treated as couples retained the gains more than parents treated as singles. 2. Fathers did not gain less than mothers. 3. Motivation remained lower for fathers throughout treatment.

More specifically, the first hypothesis suggested that couples would show more favorable outcomes than single parents. There were no differences in the pre-post measurement between the two conditions. Actually, stress and negative behavior decreased and positive behavior increased for all parents, regardless of the treatment conditions. However, the results are very different from post-follow-up measurement; while stress increased for single participating mothers it was retained for couple participating parents. Similarly, regarding coping behavior measure, participating couples managed to retain gains achieved in counseling, yet positive coping behaviors decreased (below their initial level) among parents who participated in the intervention alone, without their partners. Thus, the only significant effect concerning difference between couple and single parent treatment was observed from post to follow up. These results are important in several ways. First, fathers who participated in the treatment gained from it despite the lower motivation they show along the process, and in contrast to the reports in the literature, suggesting lower gains for fathers (Danforth et al., 2006; Fletcher et al., 2011; Treacy et al, 2005). This outcome may be attributed to the group process that manages to engage the fathers as well. Rather than trying to "fix" them through training, we suggest support and empowerment, which may suit fathers better (Fletcher et al., 2011). Once they are in the interpersonal process, they may feel less inadequate and more able to help others. Hence, fathers should be encouraged to join such programs, because they too are stressed and particularly because parenting coping style is so important for children's development (Pheula et al., 2011; Fabiano, 2007; Lonsdorf et al., 2009). Second, in the long term, fathers who participate in the treatment help their spouse to retain gains (SchoppeSullivan et al., 2009). Mothers treated as single lost gains. Relapse in therapy may be expected (Prochaska, 1999), but when both parents are treated they seem to support each other to continue with their learning. In addition, the situation at home may change. Shechtman and Gilat (2005) found that when mothers only were treated it had an effect on fathers who were not involved in treatment, let alone, when fathers are involved. For these two reasons it is important to encourage fathers to participate in treatment. Yet results show that fathers remained less motivated to engage in the group process. There are several explanations to this outcome: Fathers are in general less involved in the child's development and therefore don't perceive the child's problems as serious as mothers do (Fletcher et al., 2011). In addition, men are in general less apt to psychological treatment (Shechtman, Vogel, \& Maman, 2010). Developing ways of treatment to provide a more realistic perception of the child, and at the same time engage him in the process is important.

These results should be treated with caution because of several limitations; the most significant limitation is the small sample, particularly at post to follow-up measurement. In addition, measuring outcomes that pertain to parents only also limits the significance of the outcomes. As explained, this is part of a large and ambitious study published earlier. However, because of the growing interest in fathers' parenting and its impact on child development, it was interesting to continue researching the current questions. Future studies should be specifically designed to explore the differences between single and couple treatment utilizing larger samples, exploring samples of parents other than those with LD, measuring the lasting effect of treatment over longer periods, and studying the impact of the change in parents on their children.

The current study is an initial step to explore the impact of group therapy for mothers and fathers, specifically looking at the advantage of being treated as a couple compared to single 
treatment. Too often do we work with mothers only because fathers refrain from coming along. This study clearly shows the importance of couple participation in treatment and calls to find ways to encourage fathers to join their spouses for treatment in order to retain the gains of psychotherapy.

\section{References}

Abidin, R. R. (1995). The parenting stress index-short form. Charlottesville, VA: Pediatric Psychology Press.

Al-Yagon, M. ( 2007). Socio-emotional and behavioral adjustment among school-age children with LD: The moderating role of maternal personal resources. Journal of Special Education, 40, 205-218.

Barkley, R. A. (2006). Attention-deficit hyperactivity disorder: A handbook for diagnosis and treatment ( $3^{\text {rd }}$ Ed.). New York: Guilford.

Budd, K. S., \& O'Brien, T. P. (1982). Father involvement in behavioral parent training: An area in need of research. The Behavior Therapist, 5, 85-89.

Chronis, M., Gamble, S. A., Roberts, J. E., \& Pelham, W. E. (2006). Cognitive-behavioral depression treatment for mothers of children with attention-deficit/hyperactivity disorder. Behavior Therapy, 37, 143-158.

Clarkin, J. F., \& Levy, K. M. (2004). The influence of client variables on psychology. In M. Lambert (Ed.), Bergin and Garfield's Handbook of psychotherapy and behavior change (5th ed. Pp. 194-226). New York: Wiley.

Cunningham, C. E., Bremner, R,. \& Boyle, M. (1995). Large community-based parenting programs for families of preschoolers at risk for disruptive behavior disorder; utilization, cost effectiveness, and outcomes. Journal of Child Psychology and Psychiatry and Allied Disciplines, 36, 1141-1159.

Cussen, A., Sciberras, E., Ukoumunne, O. C. \& Efron, D., (2012). Relationship between symptoms of attentiondeficit/ hyperactivity disorder and family functioning: A community-based study. European Child \& Adolescent Psychiatry, 171, 271-280.

Danforth, J. S., Harvey, E., Ulaszek, W. R., \& McKee, T. E. (2006). The outcome of group parent training for families of children with attention-deficit hyperactivity disorder and defiant/aggressive behavior. Journal of Behavior Therapy, 37, 188-205.

Danino, M., \& Shechtman, Z. (2012). Superiority of group counseling to individual coaching for parents of children with LD. Psychotherapy Research, 22, 592-603.

Dodge, K. (2009). Community intervention and public policy in the prevention of antisocial behavior. Journal of Child Psychology and Psychiatry, 50, 194-200.

Eisenberg, N., \& Fabes, R. A. (1994). Mothers' reactions to children's negative emotions: Relations to children's temperament and anger behavior. Merril-Palmer Quarterly, 40, 138-156.

Eisenberg, N., Fabes, R. A., \& Murphy, BC. (1996). Parents' reactions to children's negative emotions: Relations to children's social competence and conforming behavior. Child Development, 67, 2227-2247.

Fabes, R. A., Eisenberg, N., \& Benzweig, J. (1990). The coping with children's negative emotional scale. Unpublished document. Tempe, AZ: Arizona State University.

Fabiano, G. A. (2007). Father participation in behavioral parent training for ADHD: Review and recommendations for increasing inclusion and engagement. Journal of Family Psychology, 21, 683-693.

Fergusson, D. M., Horwood, L. J., \& Ridder, E. M. (2005). Show me the child at seven: The consequences of conduct problems in childhood for psychological functioning in adulthood. Journal of Child Psychology and Psychiatry, 46, 837-849.

Fletcher, R., Freeman, E., \& Matthey, S. (2011). The impact of behavioral parent training on fathers' parenting: A meta-analysis of the Triple P-positive parenting program. Fathering, 9, 291-312.

Kivlighan, D. M., \& Holmes, S. E. (2004). The importance of therapeutic factors. In J.DeLucia-Waack, D. A., Garrity, C. R. Kalodner, \& M. T. Riva, (Eds). Handbook of group counseling and psychotherapy (pp. 23-360). Thousand Oaks, CA: Sage.

Lamb, M. E. (Ed), (2004). The role of the father in child development (4th Ed). New Jersey: Wiley.

Lansford, J. E., Laird, R. D., Pettit, G. S., Bates, J. E., \& Dodge, K. A. (2009).

Mothers' and fathers' autonomy-relevant parenting: Longitudinal links with adolescents' external and internal behavior. Journal of Youth and Adolescence, 43, 1877-1889. 
Miller, L. C., Berg, G. H., \& Archer, R. L., (1983). Openers: Individuals who elicit intimate self-disclosure. Journal of Personality and Social Psychology, 44, 1234-1244.

Mokrova, I., O’Brien, M., Calkins, S., \& Keane, S. (2010). Parental ADHD symptoms and ineffective parenting: The connecting link of home chaos. Parent Science and Practice, 10, 119-135.

Moran, G., Pederson, D. R., Pettit, P., \& Krupka, A. (1992). Maternal sensitivity and infant-mother attachment in a developmentally delayed sample. Infant Behavior and Development, 15, 427-442.

Parke, R. D. ( 2002). Fathers and families. In M. H. Bornstein, (Ed.) Handbook of Parenting (pp. 27-73). Mahwah, NJ: Erlbaum

Pfiffner, L. J., McBurnett, K., Rathouz, P. J., \& Judice, S. (2005). Family correlates of oppositional and conduct disorders in children with attention deficit/hyperactivity disorder. Journal of Abnormal Child Psychology, 33, 551563.

Pheula, G. F., Rohde, L. A., \& Schmitz, M. (2011). Are family variables associated with ADHD, inattentive type? A case-control study in schools. European Child and Adolescent Psychiatry, 20, 137-145.

Prochaska, J. O. (1999). How do people change, and how can we change to help many more people? In M. A. Hubble, B. I. Duncan, \& S. D. Miller (Eds.), The heart and soul of change: What works in therapy (pp. 227-257). Washington, DC: American Psychological Association.

Ryan, R. M., \& Deci, E. L. (2000). Self-determination theory and the facilitation of intrinsic motivation, social development, and wellbeing. American Psychologist, 55, 68-78.

Schoppe-Sullivan, S.J., Weldon, A. H., Cook, J. C., Davis, E. F. \& Buckley, C. K. (2009). Co-parenting behavior moderates longitudinal relations between effortful control and pre-school children's externalizing behavior. Journal of Child Psychology and Psychiatry, 50, 698-706.

Shechtman, Z. (2007). Group counseling and psychotherapy with children and adolescents. Mahwah, NJ: Erlbaum.

Shechtman, Z., \& Gilat, I. (2005). The effectiveness of counseling groups in reducing stress of parents of children with learning disabilities. Group Dynamics: Theory, Research, and Practice, 9, 275-286.

Shechtman, Z., \& Birani-Nasaraladin, D. (2006). Treating mothers of aggressive children: A research study. International Journal of Group Psychotherapy, 56, 93-112.

Shechtman, Z., Vogel, D., \& Maman, N. (2010). Seeking help: A comparison of individual and group treatment. Psychotherapy Research, 20, 30-36.

Tallman, K., \& Bohart, A. C. (1999). The client as a common factor: Clients as self-healers. In M. A. Hubble, B. L. Duncan, \& S. D. Miller (Eds.), The heart and soul of change (pp. 91-132). Washington, DC: American Psychological Association.

Toren, Z., \& Shechtman, Z. (2012). The association of personal, process, and outcome variables in group counseling: Testing an exploratory model. Group Dynamics: Theory, Research, and Practice, 14, 292-303.

Treacy, L., Tripp, G., \& Baird, A. (2005). Parent stress managing training for attention-deficit hyperactivity disorder. Behavior Therapy, 36, 223-233.

Webster-Stratton, C., \& Reid, M. J. (2010). The incredible years parent, teachers, and children training series: A multifaceted treatment approach for young children with conduct problems. In J. Weisz, \& A. Kazdin (Eds.). Evidence-based psychotherapies for children and adolescents (2 ${ }^{\text {nd }}$ ed.). New York: Guilford.

Wiggins, T. L., Sofronoff, K., Sanders, M. R. (2009). Pathways of Triple P-Positive Parenting Program: Effects on parent child relationships and child behavior problem. Family Process, 48, 517-530.

Yalom, I. D., \& Leszcz, M. (2005). The theory and practice of group psychotherapy (5th ed.). New York: Basic Books. 
Table 1

Means and standard deviations of the study variables by type of participation in group counseling (a parent / couple) and time ( $N=93$ )

\begin{tabular}{|l|c|c|c|c|c|c|}
\hline & \multicolumn{3}{|c|}{ A parent } & \multicolumn{3}{c|}{ Couple } \\
\hline & $\begin{array}{c}\text { Pre } \\
(n=47)\end{array}$ & $\begin{array}{c}\text { Post } \\
(n=47)\end{array}$ & $\begin{array}{c}\text { Follow } \\
\text { up } \\
(n=34)\end{array}$ & $\begin{array}{c}\text { Pre } \\
(n=46)\end{array}$ & $\begin{array}{c}\text { Post } \\
(n=46)\end{array}$ & $\begin{array}{c}\text { Follow } \\
\text { up } \\
(n=21)\end{array}$ \\
\hline & $M$ & $M$ & $M$ & $M$ & $M$ & $M$ \\
$(S D)$ & $(S D)$ & $(S D)$ & $(S D)$ & $(S D)$ & $(S D)$ \\
\hline PSI total & 2.62 & 2.47 & 3.07 & 2.59 & 2.43 & 2.43 \\
$(0.49)$ & $(0.56)$ & $(0.76)$ & $(0.53)$ & $(0.54)$ & $(0.73)$ \\
\hline $\begin{array}{l}\text { CCNES } \\
\text { positive } \\
\text { behaviors }\end{array}$ & 5.32 & 5.51 & 5.21 & 5.13 & 5.43 & 5.42 \\
\hline $\begin{array}{l}\text { CCNES } \\
\text { negative } \\
\text { behaviors }\end{array}$ & $(0.82)$ & $(0.85)$ & $(1.16)$ & $(0.87)$ & $(0.76)$ & $(0.93)$ \\
\hline $\begin{array}{l}\text { Intention to } \\
\text { disclose }\end{array}$ & 3.09 & 2.64 & 2.79 & 2.84 & 2.65 & 2.73 \\
\hline
\end{tabular}

Table 2

F values and effect sizes for the study variables by type of participation in group counseling (a parent / couple) and time ( $\mathrm{N}=93)$

\begin{tabular}{|c|c|c|c|c|c|c|}
\hline & \multicolumn{3}{|c|}{ Pre to post } & \multicolumn{3}{|c|}{ Post to follow up } \\
\hline & $\begin{array}{c}\text { Time } \\
F \\
\left(\eta^{2}\right)\end{array}$ & $\begin{array}{c}\text { A parent } \\
\text { / couple } \\
F \\
\left(\eta^{2}\right)\end{array}$ & $\begin{array}{c}\text { Time } x \\
\text { A parent } \\
\text { / couple } \\
F \\
\left(\eta^{2}\right)\end{array}$ & $\begin{array}{c}\text { Time } \\
F \\
F \\
\left(\eta^{2}\right)\end{array}$ & $\begin{array}{c}\text { A parent } \\
\text { / couple } \\
F \\
\left(\eta^{2}\right)\end{array}$ & $\begin{array}{c}\text { Time } x \\
\text { A parent } \\
\text { / couple } \\
F \\
\left(\eta^{2}\right)\end{array}$ \\
\hline $\begin{array}{l}\text { PSI - total } \\
\text { score }\end{array}$ & $\begin{array}{c}F(1, \\
169.13) \\
=4.17^{*} \\
(.043)\end{array}$ & $\begin{array}{c}F(1 \\
55.02)= \\
0.01 \\
(.001)\end{array}$ & $\begin{array}{c}F(1 \\
169.13) \\
=0.01 \\
(.001)\end{array}$ & $\begin{array}{c}F(1, \\
87.58)= \\
7.13^{* *} \\
(.125)\end{array}$ & $\begin{array}{c}F(1, \\
77.69)= \\
8.16^{* *} \\
(.130)\end{array}$ & $\begin{array}{c}F(1, \\
87.58)= \\
4.19^{*} \\
(.074)\end{array}$ \\
\hline $\begin{array}{l}\text { CCNES } \\
\text { positive } \\
\text { behaviors }\end{array}$ & $\begin{array}{c}F(1, \\
180.75) \\
=4.16^{*} \\
(.043) \\
\end{array}$ & $\begin{array}{c}F(1, \\
60.25)= \\
1.60 \\
(.017)\end{array}$ & $\begin{array}{c}F(1, \\
180.75) \\
=0.20 \\
(.002) \\
\end{array}$ & $\begin{array}{c}F(1, \\
87.86)= \\
0.95 \\
(.018)\end{array}$ & $\begin{array}{c}F(1, \\
88.00)= \\
0.19 \\
(.004)\end{array}$ & $\begin{array}{c}F(1, \\
87.86)= \\
5.06^{*} \\
(.082)\end{array}$ \\
\hline $\begin{array}{l}\text { CCNES } \\
\text { negative } \\
\text { behaviors }\end{array}$ & $\begin{array}{c}F(1, \\
162.87) \\
=7.60^{* *} \\
(.078)\end{array}$ & $\begin{array}{c}F(1, \\
129.47) \\
=0.24 \\
(.002)\end{array}$ & $\begin{array}{c}F(1, \\
162.87) \\
=1.26 \\
(.014)\end{array}$ & $\begin{array}{c}F(1, \\
92.10)= \\
0.56 \\
(.010)\end{array}$ & $\begin{array}{c}F(1, \\
62.68)= \\
0.62 \\
(.012)\end{array}$ & $\begin{array}{c}F(1, \\
92.10)= \\
0.14 \\
(.002)\end{array}$ \\
\hline $\begin{array}{l}\text { Intention to } \\
\text { disclose }\end{array}$ & $\begin{array}{c}F(1, \\
170.36) \\
=0.11 \\
(.001)\end{array}$ & $\begin{array}{c}F(1, \\
76.54)= \\
0.63 \\
(.005)\end{array}$ & $\begin{array}{c}F(1, \\
170.36) \\
=1.33 \\
(.015)\end{array}$ & $\begin{array}{c}F(1, \\
95.49)= \\
0.16 \\
(.003)\end{array}$ & $\begin{array}{c}F(1 \\
80.26)= \\
5.99^{*} \\
(.097)\end{array}$ & $\begin{array}{c}F(1, \\
95.49)= \\
0.12 \\
(.002)\end{array}$ \\
\hline
\end{tabular}

$* \mathrm{p}<.05, * * \mathrm{p}<.01$ 
Table 3

Means and standard deviations of the study variables by the parent's gender and time $(\mathrm{N}=93)$

\begin{tabular}{|l|c|c|c|c|c|c|}
\hline & \multicolumn{3}{|c|}{ Mothers } & \multicolumn{3}{c|}{ Fathers } \\
\hline & $\begin{array}{c}\text { Pre } \\
(n=64)\end{array}$ & $\begin{array}{c}\text { Post } \\
(n=64)\end{array}$ & $\begin{array}{c}\text { Follow } \\
\text { up } \\
(n=40)\end{array}$ & $\begin{array}{c}\text { Pre } \\
(n=29)\end{array}$ & $\begin{array}{c}\text { Post } \\
(n=29)\end{array}$ & $\begin{array}{c}\text { Follow } \\
\text { up } \\
(n=15)\end{array}$ \\
\hline & $M$ & $M$ & $M$ & $M$ & $M$ & $M$ \\
$(S D)$ & $(S D)$ & $(S D)$ & $(S D)$ & $(S D)$ & $(S D)$ \\
\hline PSI total & 2.64 & 2.48 & 2.82 & 2.52 & 2.38 & 2.83 \\
$(0.49)$ & $(0.56)$ & $(0.76)$ & $(0.55)$ & $(0.53)$ & $(0.94)$ \\
\hline $\begin{array}{l}\text { CCNES } \\
\text { positive } \\
\text { behaviors }\end{array}$ & 5.31 & 5.48 & 5.27 & 5.04 & 5.44 & 5.33 \\
\hline $\begin{array}{l}\text { CCNES } \\
\text { negative } \\
\text { behaviors }\end{array}$ & $(0.84)$ & $(0.86)$ & $(1.13)$ & $(0.84)$ & $(0.69)$ & $(0.96)$ \\
\hline $\begin{array}{l}\text { Intention to } \\
\text { disclose }\end{array}$ & 2.93 & 2.59 & 2.75 & 3.06 & 2.78 & 2.80 \\
& $(1.02)$ & $(0.77)$ & $(0.97)$ & $(0.56)$ & $(0.56)$ & $(0.84)$ \\
\hline & 3.44 & 3.54 & 3.52 & 2.98 & 2.93 & 2.65 \\
$(1.04)$ & $(1.12)$ & $(1.06)$ & $(1.06)$ & $(1.10)$ \\
\hline
\end{tabular}

